\title{
Plankton community structure and carbon cycling in a coastal upwelling system. I. Bacteria, microprotozoans and phytoplankton in the diet of copepods and appendicularians
}

\author{
Cristian A. Vargas ${ }^{1, *}$, Humberto E. González ${ }^{2}$ \\ ${ }^{1}$ Department of Oceanography, Universidad de Concepcion, Casilla 160-C, Concepcion, Chile \\ ${ }^{2}$ Institute of Marine Biology ‘Dr. Jürgen Winter', Universidad Austral de Chile, Casilla 567, Valdivia, Chile
}

\begin{abstract}
Copepod and appendicularian grazing experiments using naturally occurring planktonic assemblages from a coastal embayment (Mejillones Bay, northern Chile upwelling system at $23^{\circ} \mathrm{S}$ ) were conducted between October 2000 and October 2001. Total carbon ingestion rates based on sizefractioned chlorophyll data showed that dominant copepods (Acartia tonsa, Centropages brachiatus, Oithona similis and Paracalanus parvus) ingested between 2 and $8 \mu \mathrm{C}_{\text {ind }} .^{-1} \mathrm{~d}^{-1}$, while appendicularians (Oikopleura dioica and O. longicauda) ingested $\sim 3$ to $4 \mu \mathrm{g} \mathrm{C}$ ind.$^{-1} \mathrm{~d}^{-1}$. Even when most copepods were feeding on larger cells $(>23 \mu \mathrm{m})$ at high rates, the smaller copepods also grazed at similar rates on nanoplankton (5 to $23 \mu \mathrm{m})$ and picoplankton $(<5 \mu \mathrm{m})$. In contrast, chain-forming diatoms were cleared at very low rates by copepods. Bacteria were cleared only by appendicularians $(\sim 170$ to $\sim 400 \mathrm{ml} \mathrm{ind}^{-1} \mathrm{~d}^{-1}$ ) but not by any copepod, while heterotrophic protists constituted a substantial proportion in the diet of both copepods and appendicularians ( 10 to $100 \%$ body carbon $\mathrm{d}^{-1}$ ), particularly during austral spring. Occasionally, copepod C-specific ingestion on heterotrophs was similar to that on autotrophic cells. Large ciliates and dinoflagellates were cleared but not ingested by the appendicularian $O$. dioica, suggesting a mechanism of trapping large cells in their houses and implying a rapid export of fresh material. Since heterotrophs are a common component in the diet of these 2 groups (omnivory by copepods and bacterophagy by appendicularians), they can potentially affect microbial food webs in this upwelling system and thus carbon export.
\end{abstract}

KEY WORDS: Carbon flux $\cdot$ Omnivory $\cdot$ Microzooplankton $\cdot$ Clearance rate $\cdot$ Copepods $\cdot$ Appendicularians Resale or republication not permitted without written consent of the publisher

\section{INTRODUCTION}

Coastal upwelling systems play an important role in biological productivity and carbon cycling within oceans. While comprising a small portion of the surface area, continental margins account for more than $50 \%$ of primary productivity in the oceans (Jahnke \& Shimmield 1995). Even though the quantitative contribution of upwelling systems to carbon fluxes is still uncertain, they have a widely recognized role in global carbon export (Liu et al. 2000). As in coastal and oceanic areas, microbially dominated food webs of continental margins en- hance carbon retention in surface waters, while zooplankton activities enhance carbon export by algal grazing and production of sinking faeces (Peinert et al. 1989).

The coastal upwelling area off northern Chile is one of the major coastal upwelling regions in the Humboldt Current System (HCS). The area is a region of high production as a result of fertilization of surface waters by nutrients transported from depth during upwelling (Thomas et al. 1994, Morales et al. 1996). Most research on the fate of primary production in the Chilean upwelling system has only studied herbivory by the abundant copepod genera Calanus, Paracalanus and 
Acartia (e.g. Gonzalez et al. 2000, Grünewald et al. 2002). It is often assumed that copepods feed mostly on phytoplankton, mainly diatoms; therefore, trophic coupling between copepods and protists such as ciliates, dinoflagellates and heterotrophic nanoflagellates has been less thoroughly examined in this region. Predation by omnivorous copepods on other components of the phytoplankton and microzooplankton, especially small heterotrophic nanoflagellates and ciliates, may be important. For other coastal areas it has been suggested that protists occasionally constitute the main food source for calanoid and cyclopoid copepods (Kleppel et al. 1991, Pierce \& Turner 1992, Levinsen et al. 2000), which would have important implications for food web dynamics.

On the other hand, some attention has been given to the role of large-sized microphages, e.g. appendicularian tunicates. Appendicularians may play an important role in channeling carbon from bacteria and small-sized phytoplankton into downward export (Fortier et al. 1994). In contrast with copepods, which have long been considered the major component of secondary production in the sea, appendicularians use their mucus network to graze on bacteria, small nanoflagellates (Alldredge \& Madin 1982, Deibel \& Powell 1987), fine-grained lithogenic material (Dagg et al. 1996) or even colloidal material (Flood et al. 1992). While the biomass of appendicularians is lower than that of copepods, the production of the former is $>30$ to $100 \%$ of the latter in coastal areas (Nakamura et al. 1997, Hopcroft \& Roff 1998).

The sparse information on this group in the coastal upwelling area off northern Chile makes it is difficult to assess the quantitative and ecological importance of appendicularians in this ecosystem and to determine their position in and influence on food-web dynamics. In addition, no information is available on the feeding rates of either dominant copepods or appendicularians on microprotozoans and bacteria, or on the factors regulating their feeding in Chilean upwelling ecosystems; this precludes any speculations about their potential role in the pelagic food web.

If small-sized calanoid and cyclopoid copepods and appendicularian tunicates are able to determine or modify the fate of the production of small-sized phytoplankton and microprotozoans, they could have a significant impact on the pathway of carbon export and cycling in coastal upwelling ecosystems. In order to provide insight into this, the present study aimed to study the feeding of small copepods and appendicularians on the full food size-spectrum (phytoplankton, microprotozoan and bacteria) in a coastal upwelling area off northern Chile by measuring their clearance and ingestion rates with natural assemblages of protozoan (dinoflagellates ciliates and heterotrophic nanoflagellates) and 5 different fractions of phytoplankton (chain-forming diatoms, pennate and centric diatoms, autotrophic nanoflagellates and dinoflagellates) and bacteria.

\section{MATERIALS AND METHODS}

Feeding experiments. Experiments were conducted on 4 occasions: (1) austral spring, 17 to 22 October 2000; (2) austral summer, 9 to 10 February 2001; (3) austral winter, 1 to 2 August 2001; (4) austral spring, 21 to 22 October 2001. Copepods and appendicularians were sampled at a coastal station (Stn Exp) in Mejillones Bay $\left(23^{\circ} \mathrm{S}, 73^{\circ} 20^{\prime} \mathrm{W}\right.$; Fig. 1) by slow vertical hauls in the upper $25 \mathrm{~m}$ using a WP-2 net (mesh size $200 \mu \mathrm{m}$ ) with a large non-filtering cod-end ( 40 to $60 \mathrm{l}$ ). Immediately after collection, the contents of the codend were transferred to a thermobox and brought to the coastal laboratory in Mejillones.

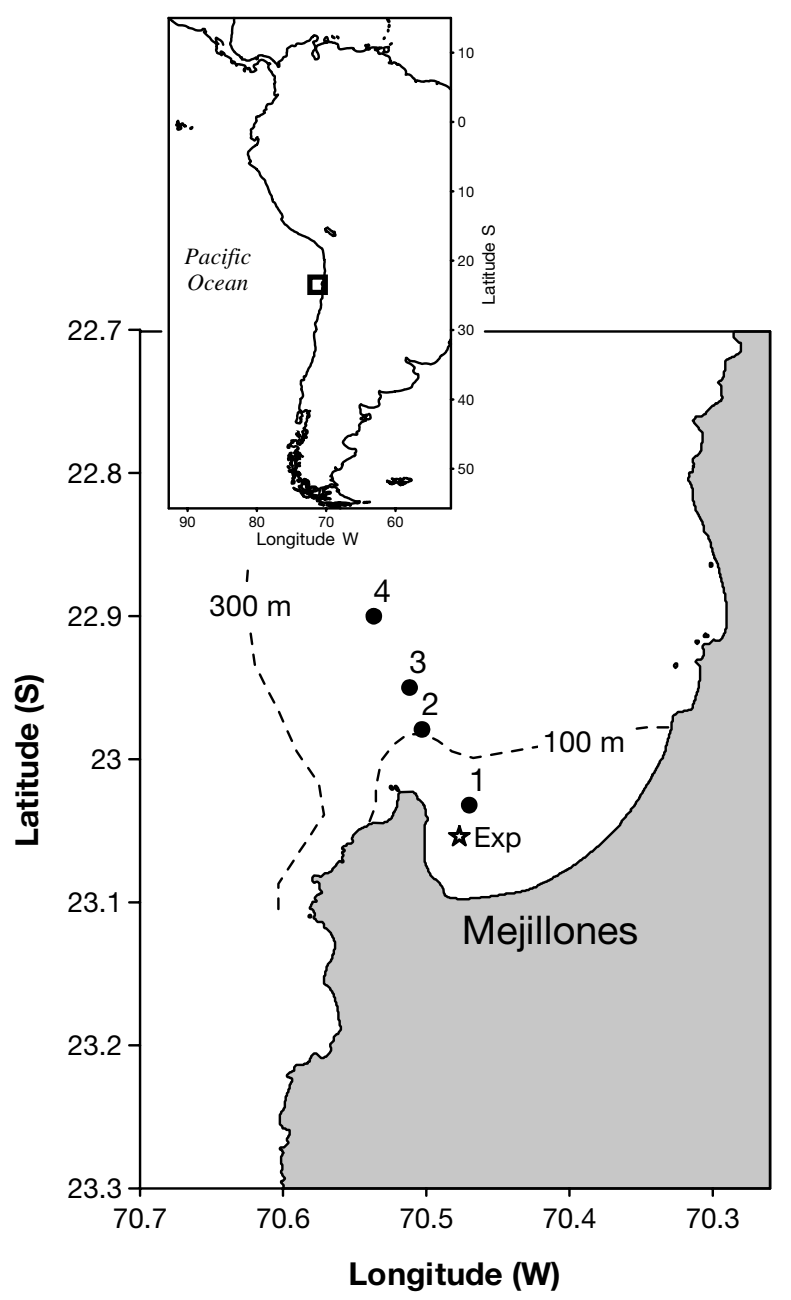

Fig. 1. Study area in Mejillones Bay showing position of the sampling station (Stn Exp) 
Within $1 \mathrm{~h}$ of collection, undamaged copepods were sorted under a stereomicroscope and appendicularians with intact houses were removed with a wide-mouth pipette and transferred to $200 \mathrm{ml}$ beakers and stored at in situ temperature until the experiment began (Table 1). Water for incubation was collected from $10 \mathrm{~m}$ with clean Teflon-coated Niskin bottles (Go-Flo, $5 \mathrm{l})$ and subsequently screened through a $200 \mu \mathrm{m}$ net to remove most grazers. The animals were pipetted into $500 \mathrm{ml}$ acid-washed polycarbonate bottles with ambient water and filled to avoid air bubbles; 3 control bottles without animals and 3 bottles with 3 to 5 individuals each were placed on a plankton rotating wheel $(0.2 \mathrm{rpm})$ in darkness at in situ temperature for approximately 15 to $20 \mathrm{~h}$. Copepod and appendicularian concentrations in the experimental bottles ranged between 6 and 10 ind. $\mathrm{l}^{-1}$ (Table 1), since during our study their abundance ranged between $\sim 300$ and 750 ind. $\mathrm{m}^{-3}$ in the upper 0 to $25 \mathrm{~m}$ layer. Initial control bottles were immediately preserved with $2 \%$ acid Lugol's solution and a subsample was preserved in glutaraldehyde $(6.0 \% \mathrm{w} / \mathrm{v}$ in $0.2 \mu \mathrm{m}$ prefiltered seawater). At the end of incubation, subsamples were taken from all bottles: $5 \mathrm{ml}$ were preserved in glutaraldehyde for determination of bacterial biomass, $20 \mathrm{ml}$ for nanoflagellate counts (when not stained immediately with proflavine) and $60 \mathrm{ml}$ were preserved with acid Lugol's solution for determination of cell concentration. In addition, for determination of size-fractioned chlorophyll a (chl a) $(<5 \mu \mathrm{m} ; 5-20 \mu \mathrm{m}$ and $>23 \mu \mathrm{m}$ ) three $100 \mathrm{ml}$ subsamples were also filtered and dark-extracted in acetone $95 \%$ before measurement on a TD 700 Turner fluorometer (Strickland \& Parsons 1972). The rest of each sample was gently poured through a $20 \mu \mathrm{m}$ sieve to collect copepods or appendicularians, their eggs and fecal pellets and appendicularian houses. The cephalothoraxic length of copepods and the trunk length of appendicularians were measured under a dissecting microscope and fecal pellets and houses were counted. The carbon content of the animals was calculated using the length-weight regressions of Klein Breteler et al. (1982: for Acartia sp. and Centropages sp.) Hirche \& Mumm (1992: for Oithona similis), Uye (1982: forother copepods), and Paffenhöfer (1976) and Gorsky et al. (1988: for Oikopleura spp.). The chl $a$ in the appendicularian houses was measured to correct ingestion rates due to particles potentially cleared from the experimental bottles but trapped in the houses.
Cell counts and calculation of clearance and ingestion rates. Nanoflagellate and bacteria samples were analysed using a color-image analysis system similar to that described by Verity \& Sieracki (1993). Samples were counted with the aid of a video camera connected to a Zeiss epifluorescence microscope and a Sony ${ }^{\circledR}$ monitor. A Windows-based imaging software package (Optimas ${ }^{\circledR}$ V. 6.0) controlled image-capture, measurement, analysis and output. Bacteria were quantified by the acridine orange technique (Hobbie et al. 1977). Bacterial volume was calculated from length and width measurements of at least 50 cells per sample. Biovolume was converted to carbon using the equation $\mathrm{C}(\mathrm{fg})$ $=90.06 \times V\left(\mu \mathrm{m}^{3}\right)^{0.59}$, where $V=$ bacterial volume (Simon \& Azam 1989, Riemann \& Bell 1990).

For the enumeration of nanoflagellates, after incubation, subsamples were immediately filtered at $0.8 \mu \mathrm{m}$ and stained with proflavine $(0.033 \% \mathrm{w} / \mathrm{v}$ in distilled water) according to Haas (1982) and fixed with glutaraldehyde (as described above) until subsequent analysis. Nanoflagellates were counted and divided into 2 groups: $<5 \mu \mathrm{m}$ and 5-20 $\mu \mathrm{m}$, and autotrophic cells were identified by autofluorescence. In October 2000 and October 2001, enumeration of nanoflagellates was done using acridine orange as fluorochrome (Davis \& Sieburth 1982).

Large cells were counted under an inverted microscope (Leica Leitz DMIL). Subsamples of $50 \mathrm{ml}$ were allowed to settle for $24 \mathrm{~h}$ in sedimentation chambers (Utermöhl 1958) before diatoms, dinoflagellates and ciliates were identified, counted and measured under the microscope. Plasma volumes were calculated (Edler 1977) and averaged from a minimum of 50 cells 
species $^{-1}$. Ciliate biovolume was calculated assuming conical shapes, with a length to diameter ratio of 1.25 for ciliates $<50 \mu \mathrm{m}$ and 2 for ciliates $>50 \mu \mathrm{m}$ (Tiselius 1989). We used carbon to plasma volume ratios of $0.11 \mathrm{pgC} \mathrm{mm}^{-3}$ for diatoms (Edler 1979), 0.3 and

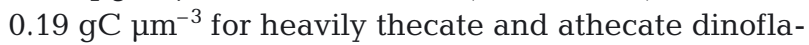
gellates forms, respectively (E. J. Lessard unpubl. data,

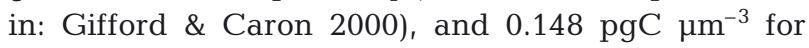
ciliates (Ohman \& Snyder 1991).

Clearance and ingestion rates were calculated according to Frost (1972) for the following groups: bacteria, autotrophic (a-) and heterotrophic (h-) nanoflagellates $(<5 \mu \mathrm{m}$ and 5-20 $\mu \mathrm{m}), \mathrm{a}-$ and h-dinoflagellates, silicoflagellates, ciliates, pennate and centric diatoms and chain-forming diatoms. Chl a ingestion was converted to carbon ingestion by multiplying by the mean carbon concentration of cells derived from 10-20 m Niskin-bottle sampling. Clearance was calculated only when the difference in prey concentration between control and experimental bottles proved to be significant (Student's $t$-test: $\mathrm{p}<0.05$, Table 2). A $Q_{10}=2.8$ was used to eliminate temperature differences among experiments (Hansen et al. 1997).

One of the biases arising from the incubation method is that the prey suspension contains several trophic levels. In order to correct for this bias, we applied a 3component equation template that considers interactions among 3 grazers in differently structured food chains (Tang et al. 2001). The values for protozoan grazing used in this template were estimated using a model proposed by Peters (1994), which includes temperature, cell volumes, and concentrations of both prey and predator as explanatory variables and predicts ingestion rates over a wide range of biological and environmental conditions. Corrections were done for the interactions bacteria-flagellates-zooplankton, flagellates-ciliates-zooplankton and diatoms-h-dinoflagellates-zooplankton.

Field cell concentration and biomass for bacteria, nanoflagellates, ciliates and phytoplankton was estimated using water samples collected from 10 to $20 \mathrm{~m}$ with clean Teflon-coated Niskin bottles (Go-Flo; 5 l). Biomass was determined using the methods described in the preceeding subsection.

\section{RESULTS}

The natural phytoplankton and protozoans provided as food varied in abundance among the experiments. During the study period, the major contribution to total biomass was by chain-forming diatoms (Fig. 2), mainly species of Chaetoceros, Guinardia, Eucampia, and Pseudonitzschia. Highest diatom biomass occurred during the August experiment $\left(8.6 \pm 3.6 \mathrm{~g} \mathrm{C} \mathrm{m}^{-2}\right)$. In October 2000, autotrophic nanoflagellates constituted a large fraction of the autotrophic biomass (2.6 \pm $0.9 \mathrm{~g} \mathrm{C} \mathrm{m}^{-2}, 32 \%$ of total autotrophs). Autotrophic and heterotrophic cells contributed equally to the nanoplankton pool ( $t$-test: $\mathrm{p}>0.05$ ), while most dinoflagellates were autotrophs ( $t$-test: $\mathrm{p}<0.05$ ), mainly represented by Ceratium and Prorocentrum species. Autotrophic (a-) dinoflagellates were more abundant in the summer and winter samples ( 2 to $4 \mathrm{gC} \mathrm{m}^{-2}$ ), when chain-forming diatoms dominated. Dinoflagellates, ciliates and bacteria were also less important in terms of biomass during our study, with highest biomass during the October 2001 sampling.

Table 2. Significance levels of difference between prey densities in control and experimental bottles (Student's $t$-test): ${ }^{* *} \mathrm{p}<0.01$, ${ }^{*} p<0.05$, ns: no significant difference. ChainD: chain-forming-diatoms; PenD: pennate diatoms; CenDand: centric diatoms; AuDino: autotrophic nanoflagellates; HeDino: heterotrophic dinoflagellates; AN: autotrophic nanoflagellates $(<5 \mu m) ; \mathrm{HN}$ heterotrophic nanoflagellates $(>5 \mu \mathrm{m})$; Bact: bacteria. Experiment dates in Table 1

\begin{tabular}{|c|c|c|c|c|c|c|c|c|c|c|c|c|c|}
\hline \multirow{2}{*}{\multicolumn{2}{|c|}{ Expt, Species }} & \multirow{2}{*}{ Chaind } & \multirow{2}{*}{\multicolumn{2}{|c|}{$\begin{array}{l}\text { Diatoms } \\
\text { PenD CenD }\end{array}$}} & \multicolumn{2}{|c|}{ Dinoflagellates } & \multirow{2}{*}{$\begin{array}{l}\text { Cili- } \\
\text { ates }\end{array}$} & \multirow{2}{*}{$\begin{array}{c}\text { Silico- } \\
\text { flagellates }\end{array}$} & \multicolumn{4}{|c|}{ Nanoflagellates } & \multirow{2}{*}{$\begin{array}{l}\text { Bact- } \\
\text { eria }\end{array}$} \\
\hline & & & & & AuDino & HeDino & & & $\mathrm{AN}>5$ & $\mathrm{HN}>5$ & $\mathrm{AN}<5$ & $\mathrm{HN}<5$ & \\
\hline \multirow[t]{3}{*}{1} & Acartia tonsa & * & * & ns & ns & ns & ns & $*$ & $* *$ & $* *$ & * & * & ns \\
\hline & Centropages brachiatus & * & * & ns & ${ }^{*}$ & ns & ${ }^{*}$ & ns & $*$ & $*$ & * & * & ns \\
\hline & Oithona similis & * & * & ns & * & $*$ & * & ns & $*$ & $*$ & * & * & ns \\
\hline \multirow[t]{3}{*}{2} & Oikopleura dioica & * & * & $*$ & $*$ & ns & * & ns & ** & $*$ & ** & $*$ & $*$ \\
\hline & Acartia tonsa & $* *$ & * & * & $* *$ & $* *$ & * & ${ }^{*}$ & $* *$ & $* *$ & $* *$ & * & ns \\
\hline & Paracalanus parvus & $* *$ & * & * & ${ }^{* *}$ & $*$ & * & ** & $*$ & $* *$ & ns & ns & ns \\
\hline \multirow[t]{3}{*}{3} & Oikopleura longicauda & $*$ & $*$ & $*$ & ${ }^{*}$ & $*$ & $*$ & * & * & ${ }^{*}$ & ${ }^{*}$ & ${ }^{* *}$ & $* *$ \\
\hline & Paracalanus parvus & $*$ & ns & * & $*$ & $* *$ & * & * & * & * & ns & ns & ns \\
\hline & Acartia tonsa & ns & $*$ & * & * & $*$ & * & * & * & * & $*$ & ns & ns \\
\hline \multirow[t]{3}{*}{4} & Oithona similis & ${ }^{*}$ & * & * & $*$ & * & * & ns & $*$ & $* *$ & $*$ & $*$ & ns \\
\hline & Centropages brachiatus & * & * & * & $* *$ & $*$ & $*$ & ns & ** & $*$ & $* *$ & * & ns \\
\hline & Paracalanus parvus & ${ }^{*}$ & * & $*$ & $* *$ & ns & $* *$ & ns & ${ }^{* *}$ & * & $*$ & * & ns \\
\hline
\end{tabular}




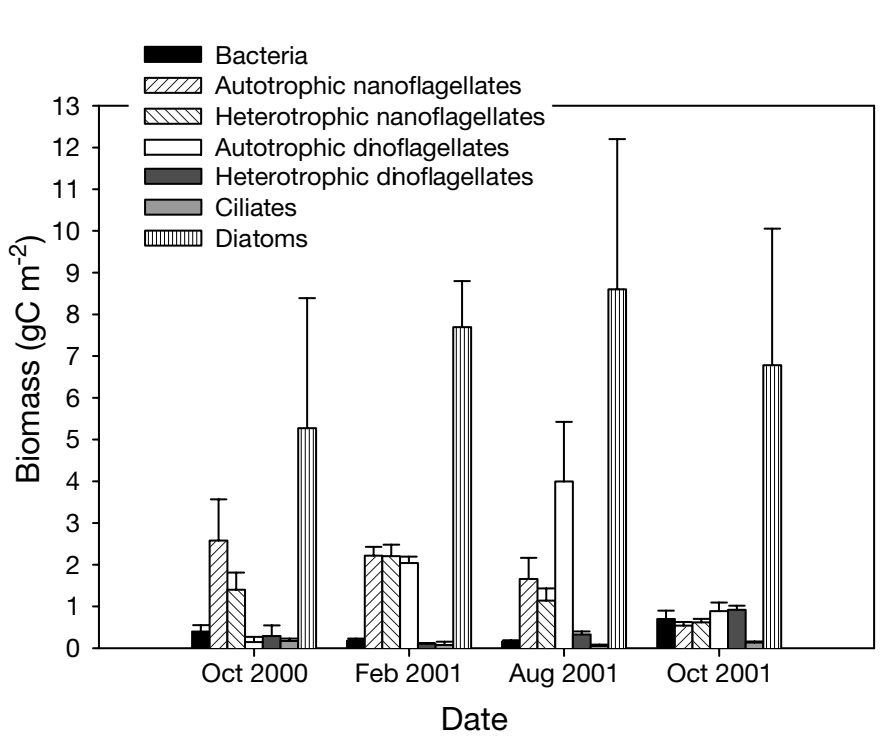

Fig. 2. Contribution of major taxonomic groups to integrated ( 0 to $25 \mathrm{~m}$ depth) biomass of autotrophic and heterotrophic community at sampling station during feeding experiments. Error bars $=\mathrm{SD}$ of replicate samples $(\mathrm{n}=3)$ carbon ingestion on h-dinoflagellates by Oithona similis was observed (Fig. 6). Predation by Acartia tonsa and $O$. similis on h-nanoflagellates and other microprotozoans (e.g. h-dinoflagellates and ciliates), resulted in heterotrophic prey contributing, on average, one-third of the total ingested carbon, the other two-thirds arising from autotrophic prey (Table 4).

Size-fractioned chlorophyll ingestion showed that in all experiments Centropages brachiatus ingested large cells $(>23 \mu \mathrm{m})$, with carbon ingestion rates relatively similar between experiments (Table 3). However, heterotrophic prey such as dinoflagellates and ciliates were always cleared faster than diatoms (Figs. 3 \& 6). A-nanoflagellates were also ingested, but only in October 2000, when they were most abundant (Fig. 2). Since h-dinoflagellates were abundant in October 2001, high clearance and ingestion of this prey was observed. In this experiment, the percentage of body carbon (BC) ingested from heterotrophs almost equalled that from autotrophs (Table 4). Similarly, Paracalanus parvus fed mostly on

\section{Copepod and appendicularian clearance and ingestion}

Grazing on natural food assemblages was relatively similar among the small-copepod species. Small copepods such as Acartia tonsa and Oithona similis did not ingest cells in proportion to their abundance. For instance, although during our study diatoms made the most important contribution to biomass (Fig. 2), size-fractioned chlorophyll ingestion by $A$. tonsa and $O$. similis showed that they were feeding mostly on the $5-23$ and $<5 \mu \mathrm{m}$ fractions respectively (Table 3 ). Cell counts showed that $A$. tonsa mostly ingested a- and h-nanoflagellates $>5 \mu \mathrm{m}$ (Figs. $3 \& 4$ ). However, during August, when a high diatom biomass was observed, A. tonsa was grazing mostly on centric diatoms $(>23 \mu \mathrm{m}$ fraction (Table 3 \& Fig. 5). At that time, carbon ingestion was the highest of all experiments. Similarly, during the October 2001 experiment, a low nanoflagellate biomass was observed and $O$. similis was also grazing on large cells $>23 \mu \mathrm{m}$, mostly centric diatoms (Fig. 6).

Since dinoflagellates and ciliates were very scarce during all experiments, clearance on h-dinoflagellates and ciliates was occasionally higher than on phytoplankton (e.g. February) and predation was so intense that ciliates were reduced to ca. $10 \%$ of their initial concentrations (data not shown). For instance, in the October 2001 experiment, high
Table 3. Carbon ingestion rates $\left(\mu \mathrm{gC}\right.$ ind.$^{-1} \mathrm{~d}^{-1}$; mean $\pm \mathrm{SD}$ ) based on size-fractioned chlorophyll data for various zooplankton species studied seasonally in Mejillones Bay. During February 2001, only fractions <23 and $>23 \mu \mathrm{m}$ were analyzed. Chl:C ratio ranged between 90 and 150

\begin{tabular}{|c|c|c|c|c|}
\hline $\begin{array}{l}\text { Species } \\
\text { Fraction }(\mu \mathrm{m})\end{array}$ & Oct 2000 & Feb 2001 & Aug 2001 & Oct 2001 \\
\hline \multicolumn{5}{|l|}{ Acartia tonsa } \\
\hline$<5$ & $0.7 \pm 0.9$ & & $0.1 \pm 0.4$ & \\
\hline $5-23$ & $1.3 \pm 0.5$ & $2.8 \pm 0.4(<23)$ & $0.1 \pm 0$ & \\
\hline$>23$ & $1.6 \pm 0.3$ & $1.2 \pm 0.2$ & $7.0 \pm 4.6$ & \\
\hline Total & $3.6 \pm 1.8$ & $4.0 \pm 0.7$ & $7.0 \pm 5.0$ & \\
\hline \multicolumn{5}{|c|}{ Centropages brachiatus } \\
\hline$<5$ & $0.5 \pm 0.2$ & & & $0.1 \pm 0.01$ \\
\hline $5-23$ & $2.5 \pm 1.7$ & & & $0.6 \pm 0.1$ \\
\hline$>23$ & $0.4 \pm 0.3$ & & & $2.9 \pm 0.3$ \\
\hline Total & $3.4 \pm 2.3$ & & & $3.6 \pm 1.5$ \\
\hline \multicolumn{5}{|l|}{ Oithona similis } \\
\hline$<5$ & $1.3 \pm 0.7$ & & & $0.1 \pm 0.1$ \\
\hline $5-23$ & $0.5 \pm 0.4$ & & & $0 \pm 0$ \\
\hline$>23$ & $0.8 \pm 0.8$ & & & $2.8 \pm 1.4$ \\
\hline Total & $2.6 \pm 1.9$ & & & $2.9 \pm 1.5$ \\
\hline \multicolumn{5}{|l|}{ Oikopleura dioica } \\
\hline$<23$ & & $3.3 \pm 0.4$ & & \\
\hline$>23$ & & $0.8 \pm 1.5$ & & \\
\hline Total & & $4.1 \pm 1.9$ & & \\
\hline Total corrected & & $3.4 \pm 1.8$ & & \\
\hline \multicolumn{5}{|c|}{ Paracalanus parvus } \\
\hline$<5$ & & & $0 \pm 0$ & $0.2 \pm 0.1$ \\
\hline $5-23$ & & $0.6 \pm 0.2(<23)$ & $0 \pm 0$ & $0 \pm 0$ \\
\hline$>23$ & & $2.5 \pm 0.7$ & $8.1 \pm 1.6$ & $3.1 \pm 0.03$ \\
\hline Total & & $3.1 \pm 0.9$ & $8.1 \pm 1.6$ & $3.3 \pm 0.1$ \\
\hline \multicolumn{5}{|c|}{ Oikopleura longicauda } \\
\hline$<5$ & & & $0.1 \pm 0.5$ & \\
\hline $5-23$ & & & $1.6 \pm 0.5$ & \\
\hline$>23$ & & & $3.6 \pm 1.5$ & \\
\hline Total & & & $5.3 \pm 2.5$ & \\
\hline Total corrected & & & $4.2 \pm 2.2$ & \\
\hline
\end{tabular}



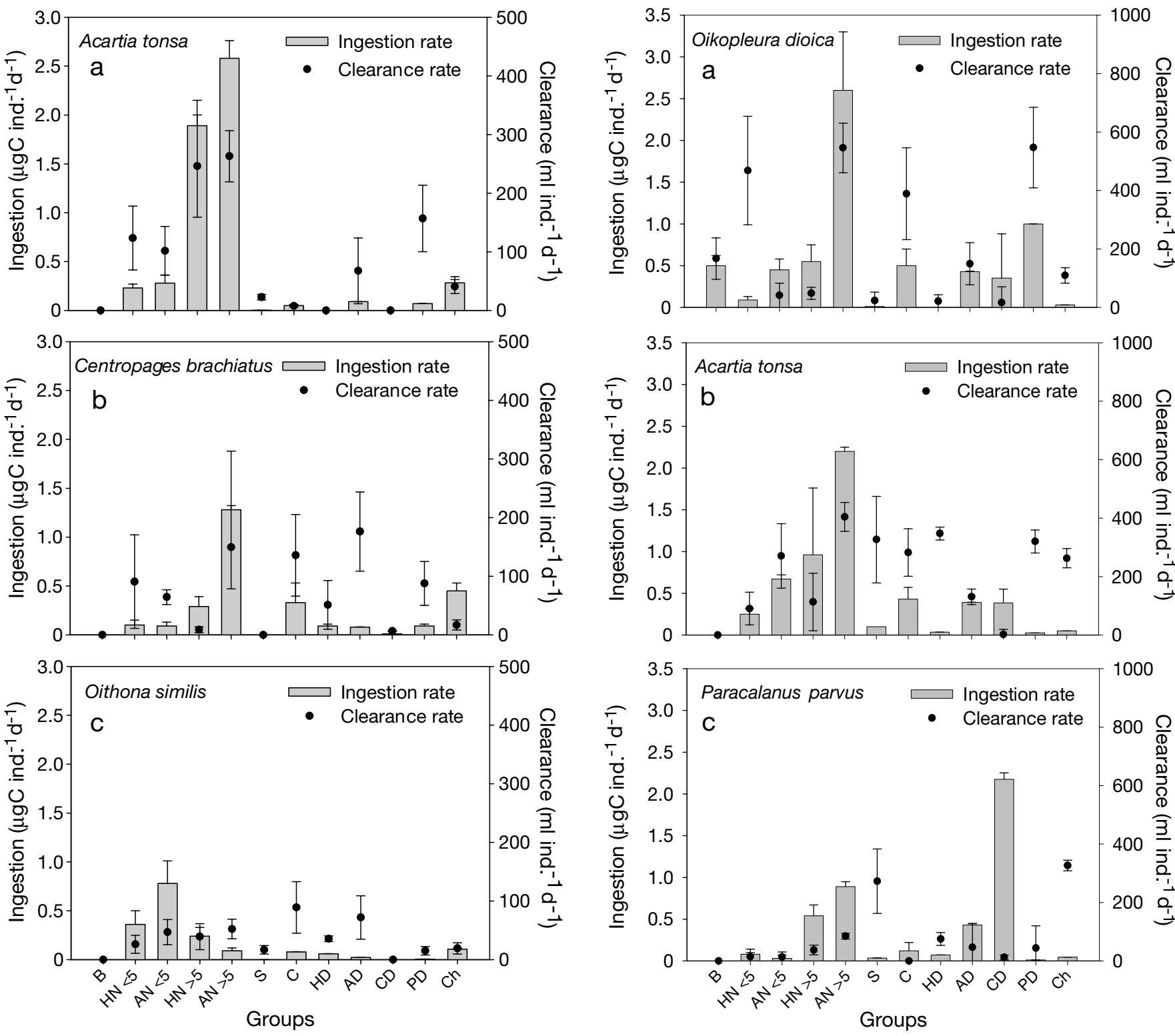

Fig. 3. Clearance and ingestion rate of major autotroph (a-) and heterotroph (h-) groups by small copepods in austral spring, October 2000. B: bacteria; HN: h-nanoflagellates; AN: a-nanoflagellates; S: silicoflagellates; C: ciliates; HD: h-dinoflagellates; AD: a-dinoflagellates; $\mathrm{CD}$ : solitary centric diatoms; PD: pennate diatoms; Ch: chain forming diatoms. $<5$ or $>5=<5$ or $>5 \mu \mathrm{m}$ cell size. Error bars $=\mathrm{SD}$ of replicate samples $(\mathrm{n}=3)$

large cells during all experiments. Nanoflagellates, ciliates and dinoflagellates were not selected by this copepod, and most of its ingested carbon originated from centric diatoms and, occasionally in October 2001, on abundant h-dinoflagellates (Figs. 4 to 6). Therefore, the high \% BC d ${ }^{-1}$ ingested by P. parvus was mostly based on autotrophic cells (Table 4 ).

Clearance of appendicularians was always higher that of copepods (Figs. $5 \& 6$ ). Despite their abundance,

Fig. 4. Clearance and ingestion rates of major autotroph and heterotroph groups by small copepods and appendicularians in austral summer, February 2001. Further details as in Fig. 3

long chain-forming diatoms were not eaten by the appendicularian Oikopleura dioica, whose highest clearance and ingestion rates were on a-nanoflagellates $>5 \mu \mathrm{m}\left(545 \mathrm{ml}\right.$ ind..$^{-1} \mathrm{~d}^{-1}$ and $2.6 \mu \mathrm{g} \mathrm{C}$ ind..$^{-1} \mathrm{~d}^{-1}$ respectively). Higher ingestion on autotrophs than heterotrophs was observed (Table 4). Another appendicularian, O. longicauda, ingested $4.2 \mu \mathrm{gC}$ ind. ${ }^{-1} \mathrm{~d}^{-1}$ during an experiment in August. Due to the low abundance of ciliates in this experiment, high clearance but low carbon ingestion was observed $\left(500 \mathrm{ml}\right.$ ind $\left.^{-1} \mathrm{~d}^{-1}\right)$ (Fig. 5). As with copepods, larger cells were also selected by $O$. longicauda and most carbon inges- 
ted also came from centric diatoms $(\sim 3.5 \mu \mathrm{gC}$ ind..$\left.^{-1} \mathrm{~d}^{-1}\right)$. O. longicauda showed the highest carbon ingestion of all species studied (auto + heterotrophs cells $=\sim 9 \mu \mathrm{g} \mathrm{C}$ ind.$^{-1} \mathrm{~d}^{-1}$ ) (Table 4). A large amount of carbon was not ingested, but was trapped and potentially exported on or into appendicularian houses $\left(0.7\right.$ and $1.1 \mu \mathrm{gC}$ ind.$^{-1} \mathrm{~d}^{-1}$ for $O$. dioica and $O$. longicauda respectively). Bacteria and small nanoflagellates $(<5 \mu \mathrm{m})$ were cleared at high rates by both appendicularian species $(\sim 200$ to $500 \mathrm{ml}$ ind..$\left.^{-1} \mathrm{~d}^{-1}\right)$, but not by any copepod ( $t$-test: $\mathrm{p}>0.05$, Table 2).

\section{Effects of cell-size and concentration on clearance}

Mean weight-specific, temperature-corrected clearance rates showed a functional response for Acartia tonsa grazing on natural food assemblages. When taking into account all particles available, clearance decreased at high carbon concentrations. However, a dome-shape curve emerged when food sources were considered separately (e.g. a- and h-nanoflagellates). Maximum clearance was $\sim 250 \mathrm{ml} \mu \mathrm{gC} \mathrm{d}{ }^{-1}$ at $19^{\circ} \mathrm{C}$ (Fig. 7a) at a concentration of $\sim 11 \mu \mathrm{gC} \mathrm{l}^{-1}$ for pennate diatoms. At high carbon concentrations, clearance decreased considerably. Maximum clearance on a- and h-dinoflagellates was $\sim 60 \mathrm{ml}$ $\mu \mathrm{gC} \mathrm{d}^{-1}$ at concentrations between 6 and $12 \mu \mathrm{gC} \mathrm{l}^{-1}$. Centric diatoms did not show any pattern and clearance of them was relatively low. Similarly, the clearance rate of Paracalanus parvus also decreased with increasing carbon concentration. Clearance of both a- and hnanoflagellates by $P$. parvus varied almost independently of prey concentration (Fig. 7b). A maximum weight-specific clearance on dinoflagellates of $\sim 200 \mathrm{ml} \mu \mathrm{gC} \mathrm{d}^{-1}$ at h-dinoflagellate concentrations around $13 \mu \mathrm{g} \mathrm{C}^{-1}$ was observed. At higher concentrations, clearance decreased considerably. Feeding on pennate and centric diatoms decreased at concentrations higher than $\sim 100 \mu \mathrm{gC} \mathrm{l}^{-1}$, with a maximum clearance of 119 and $183 \mathrm{ml} \mu \mathrm{gC} \mathrm{d}{ }^{-1}$ respectively.

The size of prey cells also had an effect on the clearance rate of copepods and appendicularians (Fig. 8). For the entire size spectrum, the volume cleared increased in a generally hyperbolic fashion for both copepods and appendicularians. Acartia tonsa grazed on all cells available, but clearance increased from about 0 to $350 \mathrm{ml} \mu \mathrm{gC} \mathrm{d}^{-1}$ within a prey size range of $\sim 0.5 \mu \mathrm{m}$ ESD (bacteria) to $\sim 85 \mu \mathrm{m}$ ESD (mainly ciliates Eutintinnus spp. and Tintinopsis spp.). However, clearance decreased when A. tonsa
Table 4. Daily ingestion rate (IR) ( $\mu \mathrm{g} \mathrm{C}$ ind.$^{-1} \mathrm{~d}^{-1}$; mean $\left.\pm \mathrm{SD}\right)$ on autotroph (A) and heterotroph $(\mathrm{H})$ cells based on cells counts. Mean zooplankton carbon content $\left(\mu \mathrm{gC}\right.$ ind $\left.{ }^{-1}\right)$ and IR as percentage of body carbon are also shown

\begin{tabular}{|c|c|c|c|c|}
\hline Species & $\begin{array}{c}\text { Trophic } \\
\text { status }\end{array}$ & $\begin{array}{c}\text { Mean IR } \\
\left(\mu \mathrm{g} C \text { ind }^{-1} \mathrm{~d}^{-1}\right)\end{array}$ & $\begin{array}{l}\text { Mean carbon } \\
\text { content } \\
\left(\mu \mathrm{g} C \text { ind } .^{-1}\right)\end{array}$ & $\begin{array}{c}\text { IR } \\
\text { (\% body } \\
\text { carbon) }\end{array}$ \\
\hline \multicolumn{5}{|l|}{ Expt 1} \\
\hline $\begin{array}{c}\text { Acartia } \\
\text { tonsa }\end{array}$ & $\begin{array}{l}\mathrm{A} \\
\mathrm{H}\end{array}$ & $\begin{array}{l}3.2 \pm 0.3 \\
2.2 \pm 0.6\end{array}$ & $\begin{array}{l}4.1 \pm 0.8 \\
4.1 \pm 0.8\end{array}$ & $\begin{array}{l}78.0 \\
53.6\end{array}$ \\
\hline $\begin{array}{c}\text { Centropages } \\
\text { brachiatus }\end{array}$ & $\begin{array}{l}\mathrm{A} \\
\mathrm{H}\end{array}$ & $\begin{array}{l}2.0 \pm 0.7 \\
0.8 \pm 0.6\end{array}$ & $\begin{array}{l}8.7 \pm 2.3 \\
8.7 \pm 2.3\end{array}$ & $\begin{array}{c}22.9 \\
9.2\end{array}$ \\
\hline $\begin{array}{l}\text { Oithona } \\
\text { similis }\end{array}$ & $\begin{array}{l}\mathrm{A} \\
\mathrm{H}\end{array}$ & $\begin{array}{l}1.0 \pm 0.3 \\
0.7 \pm 0.6\end{array}$ & $\begin{array}{l}2.0 \pm 0.1 \\
2.0 \pm 0.1\end{array}$ & $\begin{array}{l}50 \\
35\end{array}$ \\
\hline \multicolumn{5}{|l|}{ Expt 2} \\
\hline $\begin{array}{l}\text { Oikopleura } \\
\text { dioica }\end{array}$ & $\begin{array}{l}\mathrm{A} \\
\mathrm{H}\end{array}$ & $\begin{array}{l}4.9 \pm 1.3 \\
1.6 \pm 0.5\end{array}$ & $\begin{array}{l}4.1 \pm 0.8 \\
4.1 \pm 0.8\end{array}$ & $\begin{array}{l}119.5 \\
39.0\end{array}$ \\
\hline $\begin{array}{c}\text { Acartia } \\
\text { tonsa }\end{array}$ & $\begin{array}{l}\mathrm{A} \\
\mathrm{H}\end{array}$ & $\begin{array}{l}3.8 \pm 0.3 \\
1.7 \pm 1.0\end{array}$ & $\begin{array}{l}6.7 \pm 2.3 \\
6.7 \pm 2.3\end{array}$ & $\begin{array}{l}56.7 \\
25.3\end{array}$ \\
\hline $\begin{array}{l}\text { Paracalanus } \\
\text { parvus }\end{array}$ & $\begin{array}{l}\mathrm{A} \\
\mathrm{H}\end{array}$ & $\begin{array}{l}3.6 \pm 0.2 \\
0.8 \pm 0.2\end{array}$ & $\begin{array}{l}2.5 \pm 0.1 \\
2.5 \pm 0.1\end{array}$ & $\begin{array}{c}144 \\
32\end{array}$ \\
\hline \multicolumn{5}{|l|}{ Expt 3} \\
\hline $\begin{array}{l}\text { Oikopleura } \\
\text { longicauda }\end{array}$ & $\begin{array}{l}\mathrm{A} \\
\mathrm{H}\end{array}$ & $\begin{array}{l}6.9 \pm 0.9 \\
1.9 \pm 0.4\end{array}$ & $\begin{array}{l}1.6 \pm 0.1 \\
1.6 \pm 0.1\end{array}$ & $\begin{array}{l}431.2 \\
118.7\end{array}$ \\
\hline $\begin{array}{c}\text { Acartia } \\
\text { tonsa }\end{array}$ & $\begin{array}{l}\mathrm{A} \\
\mathrm{H}\end{array}$ & $\begin{array}{l}4.9 \pm 0.3 \\
0.8 \pm 0.3\end{array}$ & $\begin{array}{l}6.4 \pm 0.4 \\
6.4 \pm 0.4\end{array}$ & $\begin{array}{l}76.5 \\
12.5\end{array}$ \\
\hline $\begin{array}{l}\text { Paracalanus } \\
\text { parvus }\end{array}$ & $\begin{array}{l}\mathrm{A} \\
\mathrm{H}\end{array}$ & $\begin{array}{l}5.7 \pm 0.3 \\
1.1 \pm 0.1\end{array}$ & $\begin{array}{l}3.7 \pm 0.1 \\
3.7 \pm 0.1\end{array}$ & $\begin{array}{l}154.0 \\
29.7\end{array}$ \\
\hline \multicolumn{5}{|l|}{ Expt 4} \\
\hline $\begin{array}{l}\text { Oithona } \\
\text { similis }\end{array}$ & $\begin{array}{l}\mathrm{A} \\
\mathrm{H}\end{array}$ & $\begin{array}{l}2.8 \pm 0.1 \\
1.4 \pm 0.1\end{array}$ & $\begin{array}{l}1.2 \pm 0.4 \\
1.2 \pm 0.4\end{array}$ & $\begin{array}{l}233.3 \\
116.6\end{array}$ \\
\hline $\begin{array}{c}\text { Centropages } \\
\text { brachiatus }\end{array}$ & $\begin{array}{l}\mathrm{A} \\
\mathrm{H}\end{array}$ & $\begin{array}{l}2.8 \pm 0.3 \\
2.3 \pm 0.2\end{array}$ & $\begin{array}{l}10.4 \pm 2.3 \\
10.4 \pm 2.3\end{array}$ & $\begin{array}{l}26.9 \\
22.1\end{array}$ \\
\hline $\begin{array}{l}\text { Paracalanus } \\
\text { parvus }\end{array}$ & $\begin{array}{l}\mathrm{A} \\
\mathrm{H}\end{array}$ & $\begin{array}{l}3.7 \pm 0.3 \\
1.0 \pm 0.06\end{array}$ & $\begin{array}{l}3.7 \pm 0.4 \\
3.7 \pm 0.4\end{array}$ & $\begin{array}{c}100 \\
27\end{array}$ \\
\hline
\end{tabular}

was feeding on the large dinoflagellate Ceratium spp. (175 $\mu \mathrm{m}$ ESD). Centropages brachiatus also showed a similar pattern, but high clearance was maintained when this copepod was feeding on large cells. Small cells of $<30 \mu \mathrm{m}$ ESD (nanoflagellates and diatoms) and larger than $100 \mu \mathrm{m}$ ESD (dinoflagellates) were not efficiently cleared by Paracalanus parvus. The small cyclopoid Oithona similis was efficient at feeding on small particles. However, maximum clearance was also observed when $O$. similis were feeding on ciliates and dinoflagellates. Even though maximum clearance rates of Oikopleura dioica were also observed on large-size particles such as pennate and centric diatoms (20 to $50 \mu \mathrm{m}$ ESD) and ciliates and dinoflagellates (>70 $\mu \mathrm{m}$ ESD), these cells could not be ingested by this appendicularian, mainly because the mesh of its inlet filter is smaller $(\sim 30 \mu \mathrm{m})$ than these cells (Fenaux 1986). 

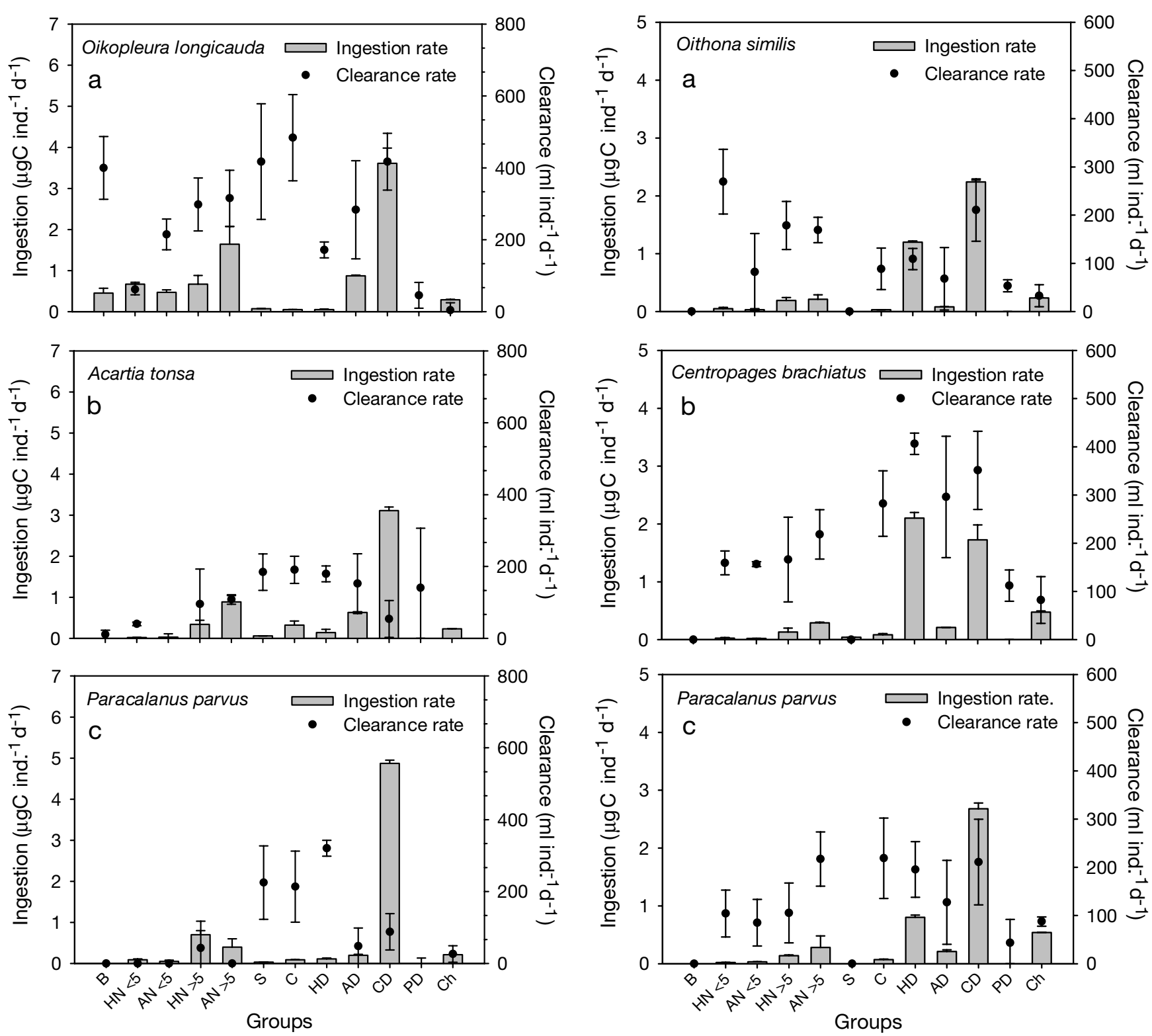

Fig. 5. Clearance and ingestion rate of major autotroph and heterotroph groups by small copepods and appendicularians in austral winter, August 2001. Further details as in Fig. 3

Fig. 6. Clearance and ingestion rate of major autotroph and heterotroph groups by small copepods in austral spring, October 2001. Further details as in Fig. 3

\section{DISCUSSION}

\section{Comparative total carbon ingestion of copepods and appendicularians}

During our study, total carbon ingestion rates based on size-fractioned chlorophyll data showed that small copepods ingested between 2 and $8 \mu \mathrm{gC}$ ind..$^{-1} \mathrm{~d}^{-1}$. (Table 3), values similar to those reported for other upwelling regions. Boyd et al. (1980) found a carbonbased ingestion rate of between 0 and $7 \mu \mathrm{gC}$ ind. ${ }^{-1} \mathrm{~d}^{-1}$ for Centropages brachiatus in the Peru upwelling

system and Paracalanus spp. ingested between 2 to $3.9 \mu \mathrm{gC}$ ind. ${ }^{-1} \mathrm{~d}^{-1}$ in the Benguela upwelling system (Peterson et al. 1988, in Verheye et al. 1992). In northern Chile, off Antofagasta, González et al. (2000) estimated an ingestion rate of 5 to $22 \mu \mathrm{gC}$ ind. ${ }^{-1} \mathrm{~d}^{-1}$ for a pool of small calanoid copepods (e.g. Temora spp., Acartia spp. and Paracalanus spp.). However, all these values were for gut-pigment content, and considered only carbon ingestion of autotrophic cells. Further, such ingestion estimates are controversial due to pigment loss to colorless, non-fluorescent compounds (Tirelli \& Mayzaud 1998). 

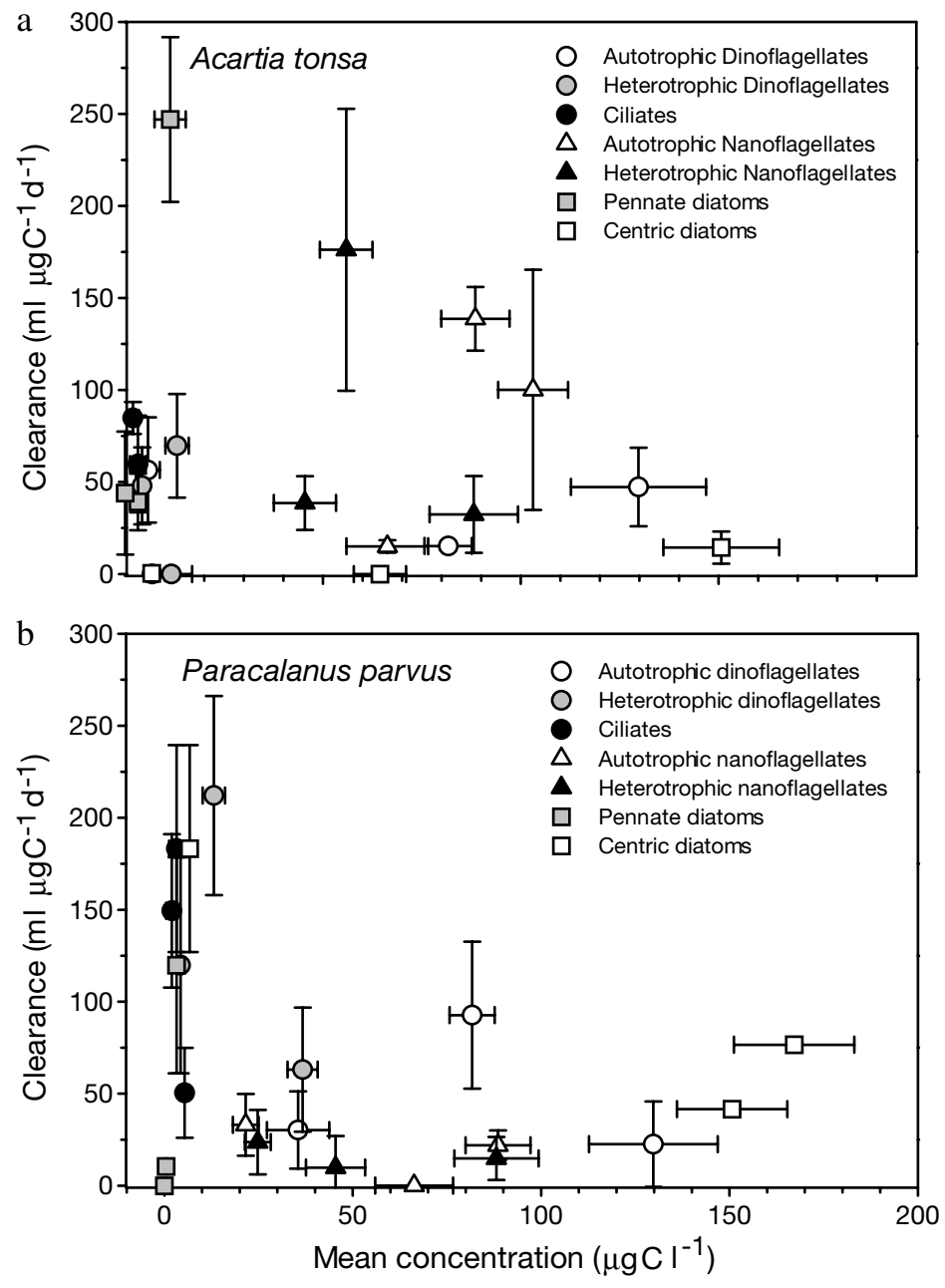

Fig. 7. Acartia tonsa and Paracalanus parvus. Weight-specific clearance of a- and h-dinoflagellates, ciliates, a- and h-nanoflagellates, pennate diatoms and centric diatoms at different natural carbon concentrations. Data were corrected to $19^{\circ} \mathrm{C}$ using a $Q_{10}$ of 2.8. Errors are \pm SE of mean

There is no prior information on appendicularians feeding in upwelling areas. In the present study, appendicularians had a chlorophyll-based ingestion of $\sim 4 \mu \mathrm{g} \mathrm{C}$ ind. ${ }^{-1} \mathrm{~d}^{-1}$. Ingestion rates of appendicularians are difficult to estimate, because some of the cells removed from suspension adhere to the house and are not ingested (Gorsky 1980). In fact, our results from corrected ingestion, $\mathrm{CI}(\mathrm{CI}=$ total chl a cleared $-\mathrm{chl} a$ trapped in houses) revealed that between 0.7 and $1.1 \mu \mathrm{gC}$ were trapped daily in appendicularian houses (house production $=\sim 5.3$ houses ind. ${ }^{-1} \mathrm{~d}^{-1}$, data not shown). This value is similar to potential ingestion by Oikopleura dioica on cells $>23 \mu \mathrm{m}\left(0.8 \mu \mathrm{g} \mathrm{C}\right.$ ind..$\left.^{-1} \mathrm{~d}^{-1}\right)$. If the inlet filter of $O$. dioica retains particles larger than $\sim 30 \mu \mathrm{m}$ (Fenaux 1986), according to the individual body size (M. Kiefer pers. comm.), then the fraction $>23 \mu \mathrm{m}$ may not be ingested, but trapped in the inlet filter of the house and therefore exported to the benthos. Apart from the exceptions mentioned previously, there are few reports on appendicularian ingestion rates in the literature. Paffenhöfer (1976) found that $O$. dioica ingests around 100 to $200 \% \mathrm{BC} \mathrm{d}^{-1}$. This is in agreement with the daily ration of $\sim 150 \%$ for $O$. dioica in our study, but much higher than the $60 \% \mathrm{BC} \mathrm{d}^{-1}$ for $O$. dioica estimated from the ingestion of radiolabeled bacterioplankton by Sorokin (1973) (around $60 \mu \mathrm{g} \mathrm{C} \mathrm{l}^{-1}$ ). However, the in situ concentration of particles in the previous studies were much lower than the average concentration of ca. 200 to $300 \mu \mathrm{gC}^{-1}$ reported for northern Chile (González et al. 2000, H. González unpubl. data), and appendicularians may not reach saturation level even at the highest natural particle concentrations (Bochdansky \& Deibel 1999). The small O. longicauda (1 mm trunk length) ingested $550 \%$ BC $\mathrm{d}^{-1}$ (i.e. auto- + heterotrophic prey). High values for daily ration in appendicularians have been also reported for other appendicularians. Deibel (1988) found that O. vanhoeffeni can ingest $980 \% \mathrm{BC} \mathrm{d}^{-1}$ in cold Newfoundland waters $\left(-2\right.$ to $\left.4^{\circ} \mathrm{C}\right)$, and estimated that its total daily ration in the Northeast Polynya would be about $250 \% \mathrm{BC} \mathrm{d}^{-1}\left(-1^{\circ} \mathrm{C}\right)$ (Deibel 1988). This indicates that clearance by appendicularians is not only high in upwelling temperate regions (i.e. $14^{\circ} \mathrm{C}$ in this study) but is also not significantly lower at very low temperatures.

\section{Contribution of bacteria, microprotozoans and phytoplankton to carbon ingestion}

Most feeding studies on copepods have shown that phytoplankton is consumed primarily in proportion to its abundance (e.g. Turner \& Tester 1989). However, the present study revealed that the less-abundant heterotrophic protists constituted a substantial proportion of the diet of both copepods (Acartia tonsa, Centropages brachiatus and Oithona similis) and appendicularians (Oikopleura dioica and O. longicauda). This microprotozoan-zooplankton coupling was particularly evident in some experiments. Even though chainforming diatoms made a major contribution to biomass, a- and h-nanoflagellates $>5 \mu \mathrm{m}$ were an important component in the diet of $A$. tonsa and $C$. brachiatus. Turner \& Granéli (1992) found similar results, with $A$. clausi and $C$. hamatus selectively grazing flagellates. In the present study, in October 2001, when a high biomass of h-dinoflagellates was observed, the trophic link between h-dinoflagellates and copepods was important to the carbon flux in the study area, as a high carbon ingestion was observed for the copepods $C$. brachiatus and Oithona similis. The C-specific ingestion of heterotrophs during this experiment was close 
to the ingestion of autotrophic cells by both $C$. brachiatus ( 2.3 and $2.8 \mu \mathrm{g} \mathrm{C}$ ind. $^{-1} \mathrm{~d}^{-1}$ respectively) and $O$. similis (1.8 and $2.8 \mu \mathrm{g} \mathrm{C}$ ind. ${ }^{-1} \mathrm{~d}^{-1}$ respectively), and almost half the body carbon ingested originated from heterotrophs ( 20 and $\left.100 \% \mathrm{BC} \mathrm{d}^{-1}\right)$. Conversely, Paracalanus parvus showed a more herbivorous strategy, as most of its ingested carbon originated from autotrophs during all study periods (Table 4). However, large prey such as dinoflagellates and ciliates were also ingested. The specific carbon clearance rates of $P$. parvus for h-dinoflagellates and ciliates were on average $\sim 100 \mathrm{ml} \mu \mathrm{gC} \mathrm{d}^{-1}$. The value for clearance of $\mathrm{h}$ dinoflagellates is comparable to that reported for $P$. parvus by Suzuki et al. (1999) (33 $\left.\mathrm{ml} \mu \mathrm{gC} \mathrm{d}^{-1}\right)$, but about 1 order of magnitude higher than for clearance of ciliates $\left(17 \mathrm{ml} \mathrm{\mu g} \mathrm{C} \mathrm{d}^{-1}\right)$.

The small cyclopoid Oithona similis cleared small aand h-nanoflagellates $<5 \mu \mathrm{m}$, which were inefficiently grazed by the other copepods. These results disagree those of Nakamura \& Turner (1997), who found that O. similis did not significantly ingest small a- and hnanoflagellates, preying instead on particles $>10 \mu \mathrm{m}$.
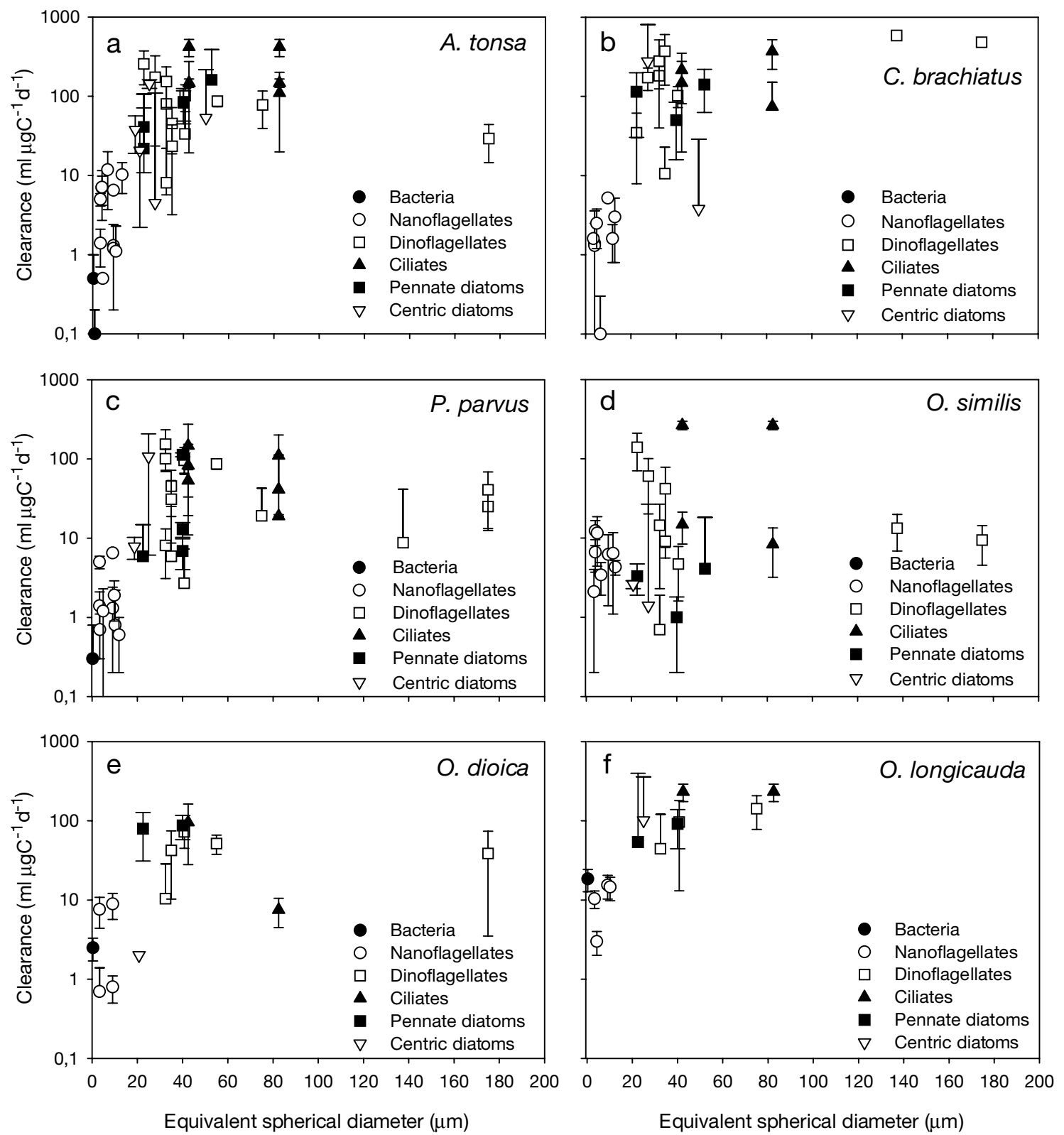

Fig. 8. Clearance by small copepods and appendicularians with different taxon-specific cell sizes of bacteria, nanoflagellates, dinoflagellates, ciliates, pennate and centric diatoms corrected to $19^{\circ} \mathrm{C}$. Errors bars are \pm SE of mean. Note log scale for clearance (y-axis) 


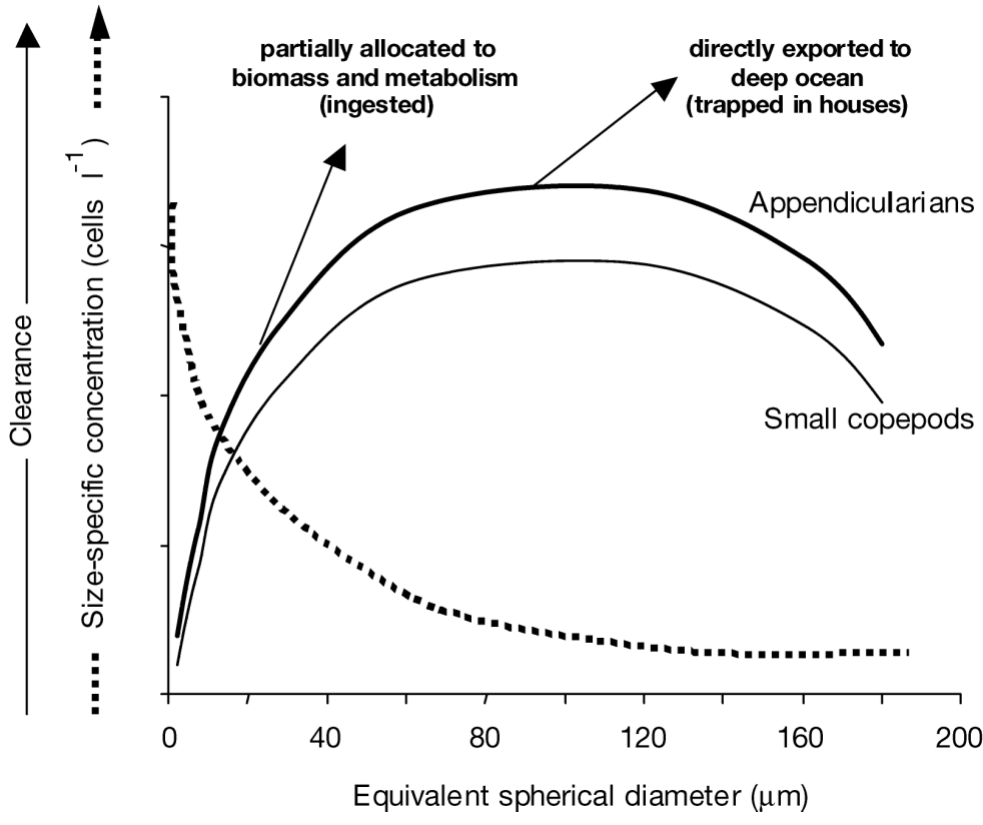

Fig. 9. Conceptual model of relationship between cell concentration and clearance rate of copepods and appendicularians in an upwelling system as a function of cell size

Our results extend the size spectrum that can be efficiently grazed by this species ( $>10 \mu \mathrm{m}$, Nakamura \& Turner 1997), and support Nielsen \& Sabatini's (1996) hypothesis that Oithona spp. may act as a link between small protozooplankton and fish larvae.

There is not previous information on feeding of appendicularians on natural assemblages of bacteria, microprotozoans and ciliates. The feeding of appendicularians on bacteria extends the size range of grazed particles, that were not available to copepods; the weight-specific clearance of appendicularians on bacteria and small flagellates was much higher than that of copepods. Although appendicularians feed on small cells, they may also affect larger cells through their unique feeding mode: Centric diatoms, as well as ciliates around $80 \mu \mathrm{m}$ ESD $\left(\sim 500 \mathrm{ml}\right.$ ind. $\left.\mathrm{d}^{-1}\right)$ were cleared at high rates by Oikopleura longicauda, but as $O$. longicauda has no incurrent filter, most large diatoms, dinoflagellates and ciliates would probably have been caugth in the filter mesh and collected on the pharyngeal filter $(610 \times 150 \mathrm{~nm}$, Deibel \& Powell 1987). Although $O$. dioica cleared pennate and centric diatoms (20 to $50 \mu \mathrm{m}$ ESD), ciliates and dinoflagellates (>70 $\mu \mathrm{m}$ ESD), these cells were probably trapped by the mesh of its inlet filter $(\sim 30 \mu \mathrm{m})$.

Chain-forming diatoms were not strongly selected by either copepods or appendicularians. Copepods were probably unable to feed on the entire large chains of the most abundant species found during our study: Eucampia cornuta, Chaetoceros spp., and Guin- ardia delicatula. However, they could feed on solitary forms such as G. delicatula (25 to $30 \mu \mathrm{m})$ during the February experiment. Schnack (1983) observed similar pattern in the northwest African upwelling area. Schnack (1983) observed that copepods were unable to feed on entire colonies of Thalassiosira partheneia (which has a cell size of about $9 \mu \mathrm{m}$ but forms colonies of up to $5 \mathrm{~cm}$ in length), but that they consumed cells once the colonies had disintegrated. One of the potential biases in our study could have been a 'food-chain effect' during incubations: as incubation proceeded, diatom growth in the experimental bottles was higher than that in controls, since diatoms in the experimental bottles were released from ciliate and h-dinoflagellate grazing pressure because these were consumed by copepods or appendicularians. This could have created an apparently low grazing rate on diatoms, even if some zooplankton grazing did actually occur. However, correction of our estimations by the 3 component equation template of Tang et al. (2001) resulted in higher grazing values on phytoplankton than uncorrected values (data not shown). A further bias in our experiments could be related to the trophic interactions between nanoflagellates being eaten by ciliates, which in turn were eaten by appendicularians. However, ciliates were very scarce during our study $\left(1.8\right.$ ciliates $\left.\mathrm{ml}^{-1}\right)$. Ciliates in control bottles could potentially remove $\sim 0.5 \mu \mathrm{gC}$ from nanoflagellates during $15 \mathrm{~h}$ incubations, while the 3 appendicularians in the experimental bottles removed around $6.3 \mu \mathrm{gC}$ during the same time. In addition, appendicularians removed around $96 \%$ of ciliate biomass in the bottles; therefore, grazing rates on nanoflagellates were underestimated by approximately $8 \%$. In consequence, we believe that trophic artifacts have been partially corrected in our clearance-rate estimates on autotrophic and heterotrophic prey.

\section{Implications of microprotozoan-zooplankton coupling in an upwelling ecosystem}

Clearance rates by Acartia tonsa generally decreased with increasing abundance of nanoflagellates, dinoflagellates and diatoms. Similar results were found for Paracalanus parvus feeding on nanoflagellates and centric diatoms. These results are in agreement with the model of the relationship between filtering rate and food concentration suggested by Marin et al. (1986), whereby clearance rate will decrease above a certain critical concentration of food. A similar pattern was found by Dagg \& Walser (1987) for Neocalanus 
plumchrus feeding on Thalassiosira weissflogii, Ohman (1987) for N. tonsus and Paffenhöfer (1988) for Paracalanus sp. Paffenhöfer (1988) suggested that the different slopes and shapes of these curves were the result of the adaptation of copepods to different trophic environments. Maximal clearance rates at different concentrations of prey suggest that copepods adapt to continuous low or high supplies of different autotrophic and heterotrophic prey of different sizes. Copepod and appendicularian ingestion of autotrophic plus heterotrophic prey typically represented more than $80 \%$ of copepod body carbon. This means that smallsized copepods and appendicularians were not foodlimited, since they are able to obtain sufficient daily rations even at low in situ chl a concentrations by feeding on many particles other than phytoplankton (González et al. 2000).

Size-dependency is well documented for copepods feeding on phytoplankton (e.g. Cowles 1979). Size-differentiated clearance rates showed that clearance rates increase with increasing prey size in a hyperbolic fashion. Since large cells such as ciliates and large dinoflagellates (i.e. from 60 to $180 \mu \mathrm{m}$ ESD) were very scarce during all our experiments, these were cleared at the highest rates, which indeed revealed a sizeselectivity by copepods (Fig. 9). Similarly, Levinsen et al. (2000) observed that Calanus spp. generally grazed ciliates more efficiently than phytoplankton, and Frost (1972) also found an increase in clearance by C. pacificus with increasing size of diatoms up to the largest species examined ( 67 $\mu \mathrm{m}$ ESD).

Although the appendicularian Oikopleura dioica feeds on small particles, it may also affect larger algae through its unique feeding mode. Therefore, there should be differences in the fate of small and large cells cleared from the bottles. For instance, while small cells such as bacteria and nanoflagellates are efficiently ingested and allocated to biomass, metabolism and fecal pellet production, cells larger than $\sim 30 \mu \mathrm{m}$ cannot be ingested by this appendicularian. Thus, even though $O$. dioca had high clearance rate of large cells, these cells probably accumulate and adhere to the house before this is abandoned and exported to the deep ocean depths (Fig. 9). Accumulation of cells on the houses of $O$. dioica could have important implications. Not only could house production dominate vertical carbon fluxes (Kiørboe et al. 1996, Vargas et al. 2002), but also sinking rates could be accelerated by the weight of attached particles, such as dinoflagellates, cells or chains that typically dominate the biomass in this upwelling area and that are too large for appendicularians to feed on.

Since clearance decreased with increasing food concentrations, but increased with increasing cell size, it seems that the clearance rate of copepods is a function of food concentration and food size, and that a copepod can vary the size range of cells ingested as a function of concentration and available cell size. This selectivity model correlates well with the size-structure of heterotrophs in this environment, where small prey (nanoflagellates) are very abundant, but large prey (dinoflagellates and ciliates) are scarce. This implies that large dinoflagellates and ciliates may be under a stronger top-down regulation than autotrophs (diatoms and nanoflagellates) in this coastal upwelling ecosystem.

Our results on feeding by small calanoid and cyclopoid copepods and appendicularians suggest that heterotrophs are a significant component of their diets. Since most studies in the Humboldt Current System have considered neither the contribution of heterotrophic microprotozoans to zooplankton grazing nor their implications for carbon fluxes (e.g. Peterson et al. 1988, Castro et al. 1991, González et al. 2000, Grünewald et al. 2002), grazing experiments on heterotrophs are needed for comparison with data based on the gutfluorescence method (Mackas \& Bohrer 1976). Given the high abundance of small copepods and appendicularians in these coastal areas (González et al. 2000, Grünewald et al. 1998), omnivory would also suppress microbial food webs, and enable zooplankton to utilize small picoplankton and convert it to exportable biogenic carbon (Zeldis et al. 2002). This important link needs to be considered in future plankton studies and food-web models of upwelling ecosystems along this coastal margin.

Acknowledgements. We wish to thank M. Pavéz, R. Giesecke and J. L. Iriarte for their help during field and laboratory work. C. Vargas was supported by the Escuela de Graduados, Universidad de Concepcion and a CONICYT doctoral fellowship during the preparation of the manuscript. We are very grateful to P. Tiselius (Kristineberg Marine Research Station, Sweden) and C. Morales (Universidad de Concepcion, Chile) for their suggestions and comments, which improved an early version of the manuscript. Special thanks to K. W. Tang and A. Visser for providing the 3-equation template and protozoan iteration template for grazing corrections. The FONDECYT Project 1000419 to H. González supported this research. Additional support from the FONDAP-COPAS Grant No. 150100007-2002 is acknowledged.

\section{LITERATURE CITED}

Alldredge AL, Madin LP (1982) Pelagic tunicates: unique herbivores in the marine plankton. BioScience 32:655-663

Bochdansky AB, Deibel D (1999) Functional feeding response and behavioural ecology of Oikopleura vanhoeffeni (Appendicularia, Tunicata). J Exp Mar Biol Ecol 233: 181-211

Boyd CM, Smith SL, Cowles TJ (1980) Grazing patterns of copepods in the upwelling system off Peru. Limnol Oceanogr 25:583-596

Castro LR, Bernal PA, González H (1991) Vertical distribution 
of copepods and the utilization of the chlorophyll a-rich layer within Concepcion Bay, Chile. Estuar Coastal Shelf Sci 32:243-256

Cowles TJ (1979) The feeding response of copepods from the Peru upwelling system: food size selection. J Mar Res 37: 601-622

Dagg MJ, Walser WE (1987) Ingestion, gut passage, and egestion by the copepod Neocalanus plumchrus in the laboratory and in the subarctic Pacific Ocean. Limnol Oceanogr 32:178-188

Dagg MJ, Green EP, McKee BA, Ortner PB (1996) Biological removal of fined-grained lithogenic particles from a large river plume. J Mar Res 54:149-160

Davis PG, Sieburth J McN (1982) Differentiation of phototrophic and heterotrophic nanoplankton populations in marine waters by epifluorescence microscopy. Ann Inst Océanogr 58 (Suppl):249-260

Deibel D (1988) Filter feeding by Oikopleura vanhoeffeni: grazing impact on suspended particles in cold ocean waters. Mar Biol 99:177-186

Deibel D (1998) Feeding and metabolism of Appendicularia. In: Bone Q (ed) The biology of pelagic tunicates. Oxford University Press, Oxford, p 139-149

Deibel D, Powell CVL (1987) Ultrastructure of the pharyngeal filter of the appendicularian Oikopleura vanhoeffeni: implications for particle size selection and fluid mechanics. Mar Ecol Prog Ser 35:243-250

Edler L (1979) Recommendations for marine biological studies in the Baltic Sea. Publ Balt Mar Biologists 5:1-38

Fenaux R (1986) The house of Oikopleura dioica (Tunicata, Appendicularia): structure and functions. Zoomorphology 106:224-231

Flood PR, Deibel D, Morris CC (1992) Filtration of colloidal melanin from sea water by planktonic tunicates. Nature 355:630-632

Fortier L, Le Fèvre J, Legendre L (1994) Export of biogenic carbon to fish and to deep ocean: the role of large planktonic microphages. J Plankton Res 16:809-839

Frost BW (1972) Effects of size and concentration of food particles on the feeding behaviour of the marine planktonic copepod Calanus pacificus. Limnol Oceanogr 17:805-815

Gifford DJ, Caron DA (2000) Sampling, preservation, enumeration and biomass of marine protozooplankton. In: Harris RP, Wiebe PH, Lenz J, Skjoldal HR, Huntley M (eds) ICES zooplankton methodology manual. Academic Press, New York, p 193-221

González HE, Sobarzo M, Figueroa D, Nöthig EM (2000) Composition, biomass and potential grazing impact of the crustacean and pelagic tunicates in the northern Humboldt Current area off Chile: differences between El Niño and non-El Niño years. Mar Ecol Prog Ser 195:210-220

Gorsky G (1980) Optimisation des cultures d'appendiculaires. Approche du metabolisme de $O$. dioica. Thése 3e cycle, Université Pierre et Marie Curie, Paris VI

Gorsky G, Dallot S, Sardou J, Fenaux R, Carré C, Palazzoli I (1988) C and N composition of some northwestern Mediterranean zooplankton and micronekton species. J Exp Mar Biol Ecol 124:133-144

Grünewald AC, Quiñones RA, Núñez S (1998) Distribución espacial y flujos de materia asociados a apendicularias (Chordata, Tunicata) en la zona centro-sur de Chile. Gayana Oceanol 6:11-23

Grünewald AC, Morales CE, González HE, Sylvester S, Castro LR (2002) Grazing impact of copepod assemblages and gravitational flux in coastal and oceanic waters off central Chile during two contrasting seasons. J Plankton Res 24: $55-67$
Haas LW (1982) Improved epifluorescence microscopy for observing planktonic micro-organisms. Ann Inst Océanogr 58:261-266

Hansen PJ, Bjørnsen PK, Hansen BW (1997) Zooplankton grazing and growth: scaling within the $2-2000-\mu \mathrm{m}$ body size range. Limnol Oceanogr 42:687-704

Hirche HJ, Mumm N (1992) Distribution of dominant copepods in the Nansen Basin, Arctic Ocean, in summer. DeepSea Res 39A (Suppl) S485-S505

Hobbie JE, Daley RT, Jasper S (1977) Use of nucleopore filters for counting bacteria by fluorescence microscopy. Appl environ Microbiol 33:1225-1228

Hopcroft RR, Roff JC (1998) Production of tropical larvaceans in Kingston Harbour, Jamaica: are we ignoring an important secondary producer? J Plankton Res 20:557-569

Jahnke RA, Shimmield GB (1995) Particle flux and its conversion to the sediment record: coastal ocean upwelling systems. In: Summerhayes CP, Emeis KC, Angel MV, Smith RL, Zeitzschel B (eds) Upwelling in the Ocean: modern processes and ancient records, John Wiley \& Sons, New York, p 83-100

Kiørboe T, Hansen JLS, Alldredge AL, Jackson GA and 5 others (1996) Sedimentation of phytoplankton during a diatom bloom: rates and mechanisms. J Mar Res 54: $1123-1148$

Klein Breteler, WCM, Fransz HG, González SR (1982) Growth and development of four calanoid copepod species under experimental and natural conditions. Neth J Sea Res 16: 195-207

Kleppel GS, Holliday DV, Pieper RE (1991) Trophic interactions between copepods and microplankton: a question about the role of diatoms. Limnol Oceanogr 36:193-198

Levinsen H, Turner JT, Nielsen, TG, Hansen BW (2000) On the trophic coupling between protists and copepods in arctic marine ecosystems. Mar Ecol Prog Ser 204:65-77

Liu KK, Iseki K, Chao SY (2000) Continental margin carbon fluxes. In: Hanson RB, Duklow HW, Field J (eds) The changing global ocean carbon cycle. International Geosphere-Biosphere Programme Book Series 5, Cambridge University Press, Cambridge, p 187-239

Mackas D, Bohrer R (1976) Fluorescence analysis of zooplankton gut contents and investigation of diel feeding patterns. J Exp Mar Biol Ecol 25:77-85

Marin V, Huntley ME, Frost B (1986) Measuring feeding rates of pelagic herbivores: analysis of experimental design and methods. Mar Biol 93:49-58

Morales C, Blanco J, Braun M, Reyes H, Silva N (1996) Chlorophyll-a distribution and associated oceanographic conditions in the upwelling region of northern Chile during the winter and spring 1993. Deep-Sea Res 43:267-289

Nakamura Y, Turner JT (1997) Predation and respiration by the small cyclopoid copepod Oithona similis: how important is feeding on ciliates and heterotrophic flagellates? J Plankton Res 19:1275-1288

Nakamura Y, Suzuki K, Suzuki S, Hiromi J (1997) Production of Oikopleura dioica (Appendicularia) following a picoplankton 'bloom' in a eutrophic coastal area. J Plankton Res 19:113-124

Nielsen TG, Sabatini M (1996) Role of cyclopoid copepods Oithona spp. in North Sea plankton communities. Mar Ecol Prog Ser 139:79-93

Ohman MD (1987) Energy sources for recruitment of the subantarctic copepod Neocalanus tonsus. Limnol Oceanogr 32:1317-1330

Ohman MD, Snyder RA (1991) Growth kinetics of the omnivorous oligotrich ciliate Strombidium sp. Limnol Oceanogr 36:922-935 
Paffenhöfer GA (1976) On the biology of Appendicularia of the southern North Sea. In: Persoone G, Jaspers E (eds) Proc 10th Europ Symp Mar Biol. Universa Press, Wetteren, Belgium, p 437-455

Paffenhöfer GA (1988) Feeding rates and behavior of zooplankton. Bull Mar Sci 43:430-445

Peinert R, von Bodungen B, Smetacek V (1989) Food web structure and loss rate. In: Berger WH Smetacek VS, Wefer G (eds) Productivity of the ocean: present and past. John Wiley \& Sons, New York, p 35-48

Peters F (1994) Prediction of planktonic protistan grazing rates. Limnol Oceanogr 39:195-206

Peterson WT, Arcos DF, McManus GB, Dam H, Bellantoni D, Johnson T, Tiselius P (1988) The nearshore zone during coastal upwelling: daily variability and coupling between primary and secondary production off central Chile. Prog Oceanogr 20:1-40

Pierce RW, Turner JT (1992) Ecology of planktonic ciliates in marine food webs. Rev Aquat Sci 6:139-181

Riemann B, Bell RT (1990) Advances in estimating bacterial biomass and growth in aquatic systems. Arch Hydrobiol 25:385-402

Schnack SB (1983) On the feeding of copepods on Thalassiosira partheneia from the northwest African upwelling area. Mar Ecol Prog Ser 11:49-53

Simon M, Azam F (1989) Protein content and protein synthesis rates of planktonic marine bacteria. Mar Ecol Prog Ser 51:201-213

Sorokin YI (1973) Quantitative evaluation of the role of bacterioplankton in the biological productivity of tropical Pacific waters. In: Norgradov MEV (ed) Life activity of pelagic communities in the ocean tropics, Program for Israel Scientific Translations, Jerusalem, p 98-135

Strickland JD, Parsons TR (1972) A practical handbook of seawater analysis, 2nd edn. Bull Fish Res Board Can 167

Suzuki K, Nakamura Y, Hiromi J (1999) Feeding by the small calanoid copepod Paracalanus sp. on heterotrophic dinoflagellates and ciliates. Aquat Microb Ecol 17:99-103

Tang KW, Jakobsen HH, Visser AW (2001) Phaeocystis globosa (Prymnesiophyceae) and the planktonic food web: feeding, growth, and trophic interactions among grazers.

Editorial responsibility: John Dolan, Villefranche-sur mer, France
Limnol Oceanogr 46:1860-1870

Thomas A, Strub T, Huang F, James C (1994) A comparison of the seasonal and interannual variability of phytoplankton pigment concentration in the Peru and California Current systems. J Geophys Res 99:7355-7370

Tirelli V, Mayzaud P (1998) Gut pigment destruction by the copepod Acartia clausi. J Plankton Res 20:1953-1961

Tiselius P (1989) Contribution of aloricate ciliates to the diet of Acartia clausi and Centropages hamatus in coastal waters. Mar Ecol Prog Ser 56:49-56

Turner JT, Granéli E (1992) Zooplankton feeding ecology: grazing during enclosure studies of phytoplankton blooms from the west coast of Sweden. J Exp Mar Biol Ecol 157: $19-31$

Turner JT, Tester PA (1989) Zooplankton feeding ecology: nonselective grazing by the copepods Acartia tonsa Dana, Centropages velificatus De Oliveira, and Eucalanus pileatus Giesbrecht in the plume of the Mississippi River. J Exp Mar Biol Ecol 126:21-43

Utermöhl H (1958) Zur Vervollkommnung der quantitativen Phytoplankton-Methodik. Mitt Int Ver Theor Angew Limnol 9:1-39

Uye SI (1982) Length-weight relationships of important zooplankton from the Inland Sea of Japan. J Oceanogr Soc Jpn 38:149-158

Vargas CA, Tönnesson K, Sell A, Maar M and 8 others (2002) The importance of copepods versus appendicularians in vertical carbon fluxes in a Swedish fjord. Mar Ecol Prog Ser 241:125-138

Verheye HM, Hutchings L, Huggett JA, Painting SJ (1992) Mesozooplankton dynamics in the Benguela ecosystem, with emphasis on the herbivorous copepods. S Afr J Mar Sci 12:561-584

Verity PG, Sieracki ME (1993) Use of color image analysis and epifluorescence microscopy to measure plankton biomass. In: Kemp PF, Sherr BF, Sherr EB, Cole JJ (eds) Handbook of methods in aquatic microbial ecology. Lewis, London, p $327-338$

Zeldis J, Jjames MR, Grieve J, Richards L (2002) Omnivory by copepods in the New Zealand Subtropical Frontal Zone. J Plankton Res 24:9-23

Submitted: September 15, 2002; Accepted: September 15, 2003 Proofs received from author(s): January 27, 2004 